Journal of Engineering and Applied Sciences 14 (12): 4183-4190, 2019

ISSN: 1816-949X

(C) Medwell Journals, 2019

\title{
Rutting Resistance Potential of High Modulus Asphalt Concrete Pavements
}

\author{
Ali Abdulkhaleq Mahdi and Mohammed Qadir Ismael \\ Department of Civil Engineering, University of Baghdad, Baghdad, Iraq
}

\begin{abstract}
The High Modulus Asphalt Concrete Mixture (HMACM) or (EME) (Enrobes a Module Eleve) developed in France, since, 1980 by Labatories Central des Ponts et Chaussees (LCPC). Due to the increasing in traffic intensity and axle loading this type of mixing were suitable for pavement subjected to heavy duty. Experiments showed that EME mixtures have an excellent moisture damage resistance permanent deformation, fatigue cracking and reducing costs of maintenance and a significant reduction in thickness of pavement. Because of the high stiffness of EME mixes, the stresses transformed to the bottom laid layer by repeated traffic wheel loads were reduced effectively. This study intend to focus the light into the possibility of producing asphalt mixtures (EME1) and (EME2) that exhibit high degree of high stiffness in order to with stand against the initiation of rutting. The evaluation process will be based on conducting the pneumatic repeated load system and the wheel-tracking test. For this purpose, hard asphalt cement with a penetration grade of 20-30 for EME comparing with conventional asphalt cement with penetration grade of 40-50. The results obtained indicates that increasing the temperature from $\left(25\right.$ to $\left.4^{\circ} \mathrm{C}\right)$, Resilient Modulus $\left(\mathrm{M}_{\mathrm{r}}\right)$ reduced by 65 and $20 \%$ for conventional and (EME) for base course while at the binder course the resilient modulus reduced by 59 and $16 \%$ for conventional and (EME), respectively. Wheel track test results showed that permanent deformation increased significantly with hard penetration grade bitumen, the rut depth was $2.55 \mathrm{~mm}$ while for conventional bitumen was $16.15 \mathrm{~mm}$ for base course. While at binder course the rut depth was $2.43 \mathrm{~mm}$ while for conventional bitumen was $15.1 \mathrm{~mm}$. This increasing in rutting resistance important for reducing and preventing structural failure and in other hand for economy and reducing layer thickness.
\end{abstract}

Key words: High modulus asphalt concrete mixture, resilient modulus, wheel tracking test, EME1, EME2, LCPC

\section{INTRODUCTION}

For road constructions and pavements for airport (HMAC) is significant solution due to higher amount of hard binder, thus, reducing the thickness of layer due to higher capacity and stiffness were achieved and the stresses causing by traffic and transformed to the bottom layer were reduced. Both distresses of compressive strain occurred in the top of subgrade and distresses of tensile strain occurred at the bottom of the pavement layer were minimized due to high stiffness of (HMAC) (Moreno-Navarro et al., 2014). High modulus asphalt (EME) mixture have a large amount of binder content and using in binder layer and base layer. Performance of this type of mixture were have higher resistance to rutting, higher resistance to fatigue, higher stiffness, higher resistance to moisture and workable (Sanders and Nunn, 2005). Because of visco elastic properties of binder materials, the materials are varying from viscous consistency to elastic depending upon temperature and time of loading. The properties of binder can be expressed in relation to viscosity at higher temperature, especially during the procedure of mixing and compaction of binder but overwhelmingly binder acts as visco elastic and their stiffness modulus play a significant roll and effecting on properties of mixtures (Hunter et al., 2015) one preferable solution without increasing thickness of base course is using (HMAC) for long performance life. Reducing thickness achieved by increasing binder stiffness and conducted by using hard grade asphalt for (HMAC) (Lee et al., 2007). This type of mixture used in France widely for base course and binder course for rehabilitations, new road constructions, buried pipes and curbs because of high stiffness, high reduction in pavement thickness and economy as shown in Fig. 1 (Corte, 2001).

Background: LCPC developed High Modulus Asphalt Concrete Mixture (HMACM) for increasing the rigidity of the mixture and reducing mitigation of rutting for base

Corresponding Author: Ali Abdulkhaleq Mahdi, Department of Civil Engineering, University of Baghdad, Baghdad, Iraq 
course and binder course under the specification of NF P 98-140. Air void content for EME2 is lower than at EME1 because of higher percent of binder (defined according to richness modulus) (Wu et al., 2011). The additives of hard asphalt play a significant role in the developing of the rut resisting performance of asphalt mix. Pavement as it increases the rigidity and reduces the rutting mitigation problem, hard binder used for bottom layer (binder an base course) and covering with wearing to prevent and stable thermal effect (Wu et al., 2010). The high modulus binder produce within these three categories which is refinery produced hard binder modified by asphaltite high modulus asphalt binder modified by polyolefin (Geng et al., 2013 ). For the last 20 years, France was the first country to use hard binder in their pavement. Base course rigidity were increased by using this type of binder, maintenance and road construction were decreased. France are in leading country for using this binder type (Corte, 2001).

\section{MATERIALS AND METHODS}

Experimental work: Several of laboratory tests were carried out, first to investigate the high modulus asphalt and compared to conventional asphalt, then on the high modulus asphalt mixture including, resilient modulus and wheel tracking test.

Asphalt cement test: Two types of asphalt cement (20-30) and (40-50) brought from Daurah refinery were used in this study. All test results meet the Iraqi specification (SCRB., 2003). Physical properties of asphalt cement shown in Table 1-3.

Materials and preparation of asphalt mixtures specimens: In this study, for producing asphalt mixture specimens, hard asphalt with penetration grade (20-30) for preparing EME mixtures and conventional asphalt (40-50) were used for comparison for both asphalt type. Physical properties of these binder were presented in Table 2. Depend upon aggregate selected size for EME were designated to be either $(0 / 10)$ or $(0 / 14)$ or $(0 / 20)$ (AFNOR., 1999), according to selected aggregate size for base course the suitable gradation was $(0 / 20)$ and $(0-14)$ for
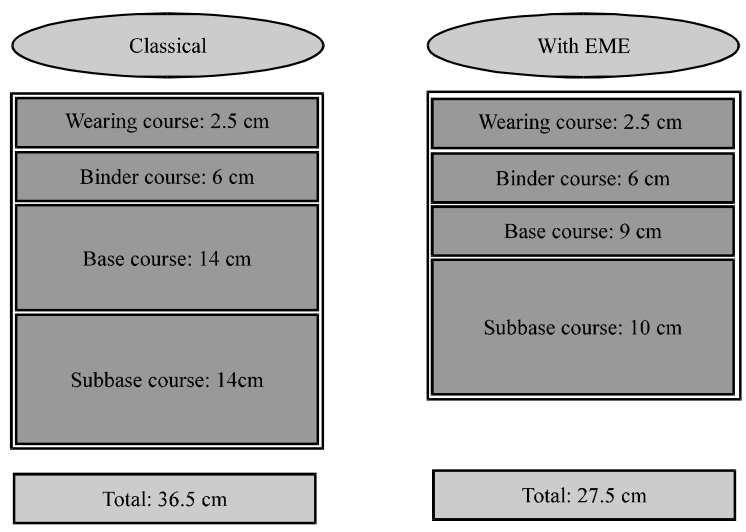

Fig. 1: Comparison of HMAC and traditional AC solution for full-depth asphalt pavement 1998 french road directorate catalogue (Reduction 25\% (Corte, 2001)

Table 1: Plan test

Type of test

Marshall test

Resilient modulus test

Wheel tracking test Purpose

Finding optimum bitumen content for EME and conventional mixture Influence of temperature on resilient modulus behaviour with different asphalt cement Rutting depth and related to mixtures properties

Table 2: Physical properties of asphalt cement

\begin{tabular}{|c|c|c|c|c|c|}
\hline Tests & Units & $\begin{array}{c}\text { ASTM } \\
\text { designation No. }\end{array}$ & $\begin{array}{c}\text { Penetration grade } \\
\text { of conventional }(40-50)\end{array}$ & SCRB specification & Penetration grade of EME (20-30) \\
\hline Penetration@ $\left(25^{\circ} \mathrm{C}, 100 \mathrm{~g}, 5 \mathrm{sec}\right)$ & $1 / 10 \mathrm{~mm}$ & D-5 & 44 & $40-50$ & 21 \\
\hline Softening point.(Ring and Ball) & $\left({ }^{\circ} \mathrm{C}\right)$ & D-36 & 42 & - & 61 \\
\hline Specific gravity@2 $25^{\circ} \mathrm{C}$ & - & D-70 & 1.041 & - & 1.037 \\
\hline Ductility@ $\left(25^{\circ} \mathrm{C}, 5 \mathrm{~cm} / \mathrm{min}\right)$ & $\mathrm{cm}$ & D-113 & 116 & $>100$ & 18 \\
\hline Flash point (cleveland open cup) & $\left({ }^{\circ} \mathrm{C}\right)$ & D-92 & 260 & 232 (Min.) & 300 \\
\hline \multicolumn{6}{|l|}{ After thin-film oven test ASTM D 1754} \\
\hline $\begin{array}{l}\text { Retained penetration of residue } \\
\left(25^{\circ} \mathrm{C}, 100 \mathrm{~g}, 5 \mathrm{sec}\right)\end{array}$ & $\%$ & D-5 & 66 & 55 (Min.) & 75 \\
\hline Softening point (Ring and Ball) & $\left({ }^{\circ} \mathrm{C}\right)$ & D-36 & 51 & - & 68 \\
\hline
\end{tabular}

Table 3: Physical properties of coarse aggregate

\begin{tabular}{lccc}
\hline Properties & ASTM designation No. & Coarse aggregate & SCRB specification \\
\hline Bulk specific gravity & C-127 & 2.600 & - \\
Apparent specific gravity & C-127 & 2.644 & - \\
Percent water absorption & C-127 & 0.435 & - \\
Percent wear (los angeles abrasion \%) & C-131 & 19.690 & $30 \mathrm{Max}$ \\
\hline
\end{tabular}


Table 4: Phy sical properties of fine aggregate

\begin{tabular}{lccc}
\hline Properties & ASTM designation No. & Fine aggregate & Specification SCRB \\
\hline Bulk specific gravity & C-128 & 2.640 & - \\
Apparent specific gravity & C-128 & 2.652 & - \\
Percent water absorption & C-128 & 0.562 & - \\
\hline
\end{tabular}

Percent water absorption

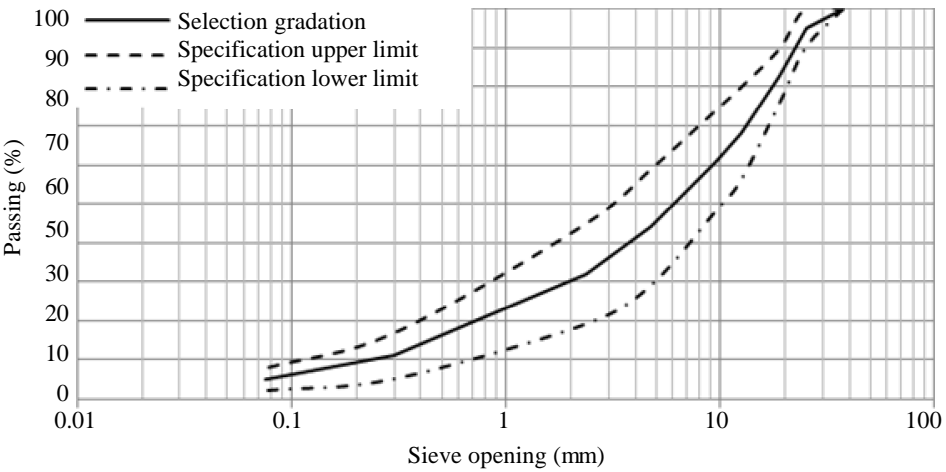

Fig. 2: Aggregate gradation for conventional mixture for base course

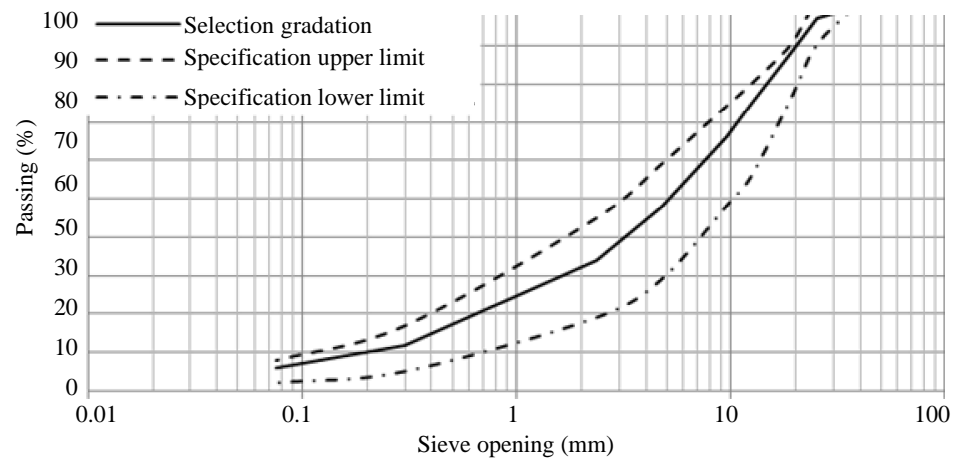

Fig. 3: Aggregate gradation for EME mixture for base course

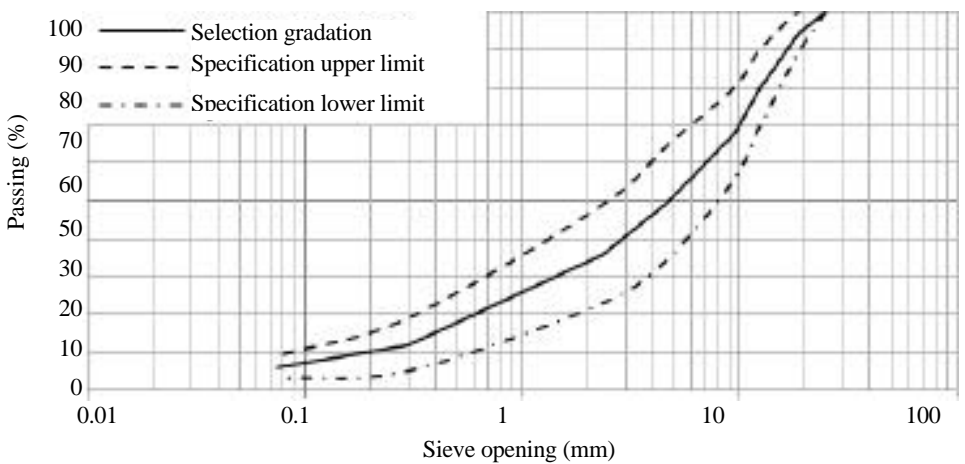

Fig. 4: Aggregate gradation for conventional mixture for binder course

binder course and both gradation of EME and conventional were within the Iraqi specification for roads and bridges with a $25-19 \mathrm{~mm}$ nominal maximum size of aggregate as shown in Fig. 2-5. Coarse crushed aggregate from Amant Baghdad mix plant (alobaidy hot mix plant) were used the physical properties of coarse crushed aggregate were presented in Table 3. Natural sand was used as fine aggregate which was brought from the
Karbala quarry and physical properties presented in Table 4. Limestone dust was used as mineral filler, lime factory in governorate Karbala was source of limestone dust and physical properties presented in Table 5. The Marshall design method was adopted to find optimum binder content for EME and conventional mixture. Optimum content for conventional mixture was $3.9 \%$ while for EME mixture was $4.7 \%$ for base 


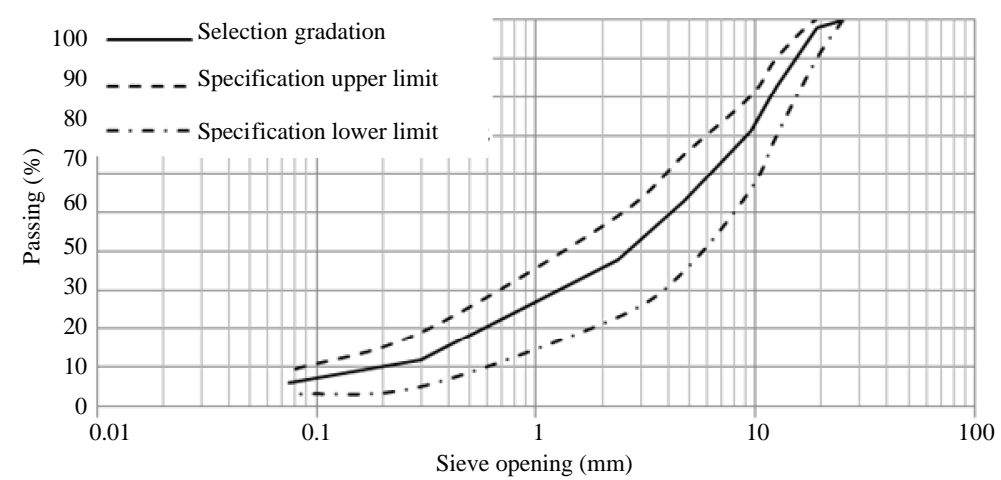

Fig. 5: Aggregate gradation for EME mixture for binder course

Table 5: Physical properties of limestone dust

\begin{tabular}{lc}
\hline Properties & Limestone \\
\hline Passing No. $200(\%)$ & 96.00 \\
Specific gravity & 2.68 \\
\hline
\end{tabular}

course while at binder course optimum content for conventional mixture was $4.5 \%$ while for EME mixture was $5.2 \%$.

\section{RESULTS AND DISCUSSION}

Resilient modulus test: The test was conducting by the pneumatic repeated load system, by applying repeated axial load on a cylinder specimen of (4 in) in diameter and (6 in) in height according to (Witczak, 2002). The Resilient Modulus ( $M_{+}$) is consider the main parameter for the designe of the asphalt pavemment layer as by determination the resilient modulus for the materials of the pavement layers, it gives an indication of how pavment layers respond to different traffic loadings. The permanent deformation measured by using Linear Variable Differential Transducer (LVDT). The shape of loading was rectangular wave load with frequency of $0.1 \mathrm{sec}$. Loading and 0.9 resting load with a load frequency of 60 cycles/min as specified by Albayati (2006).

Resilient modulus test results: The test procedure was first for the temperature in the specimens in well distribution, the specimens were for $2 \mathrm{~h}$ placed in device chamber and then starting the test. The Resilient Modulus is $\left(\mathrm{M}_{\mathrm{r}}\right)$ calculated according to the formula bellow (Huang, 1993):

$$
\mathrm{M}_{\mathrm{r}}=\frac{\sigma}{\varepsilon_{\mathrm{r}}}
$$

Where:

$\mathrm{M}_{\mathrm{r}}=$ Resilient Modulus

。 $=$ Repeated axial stress

${ }_{\mathrm{r}}=$ Axial resilient strain

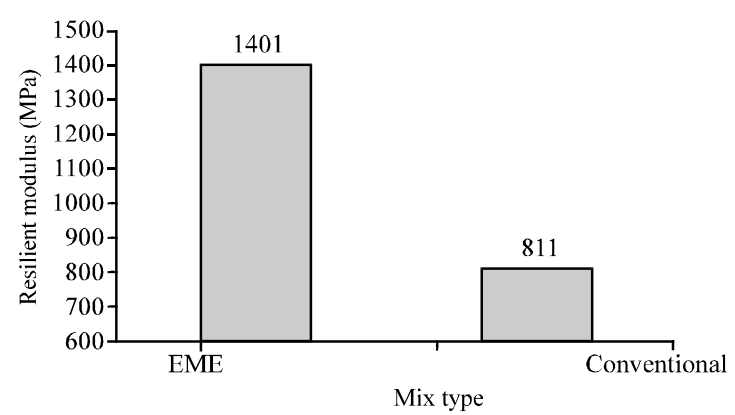

Fig. 6: Effect of temperature on resilient modulus@25 $\mathrm{C}$ for base course

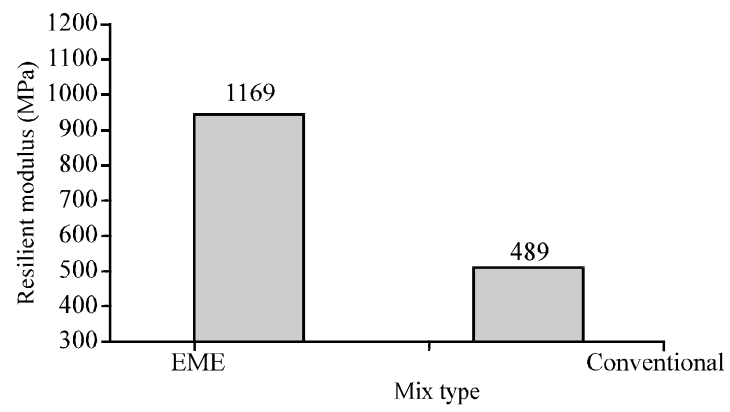

Fig. 7: Effect of temperature on resilient modulus@ $40^{\circ} \mathrm{C}$ for base course

The resilient modulus at $25^{\circ} \mathrm{C}$ is not required because of high stiffness of high modulus asphalt concrete mixtures (Dias et al., 2017). This can be observed from Fig. 6-9, the resilient modulus is influenced with temperatures and type of mixtures. The test results showed at base course that the resilient modulus for (HMAC) were 1401 and $1169 \mathrm{MPa}$ at temperature of 25 and $40^{\circ} \mathrm{C}$, respectively while for conventional mixture the resilient modulus were 811 and $489 \mathrm{MPa}$ at temperature of 25 and $40^{\circ} \mathrm{C}$, respectively. At binder course that the 


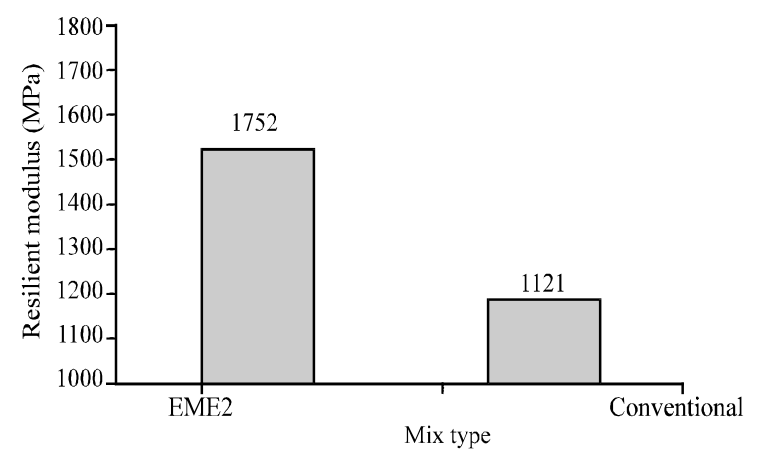

Fig. 8: Effect of temperature on resilient modulus@ $25^{\circ} \mathrm{C}$ for binder course

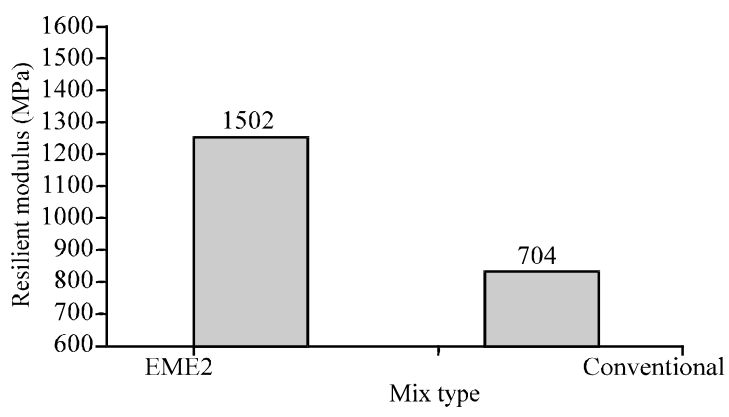

Fig. 9: Effect of temperature on resilient modulus @ $40^{\circ} \mathrm{C}$ for binder course

resilient modulus for (HMAC) were 1752 and $1502 \mathrm{MPa}$ at temperature of 25 and $40^{\circ} \mathrm{C}$, respectively while for conventional mixture the resilient modulus were 1121 and $704 \mathrm{MPa}$ at temperature of 25 and $40^{\circ} \mathrm{C}$, respectively. As increased, the temperatures resilient modulus decreased and this because of that the asphalt cement is very susceptible to temperature, the asphalt stiff and brittle at low temperatures but soft and ductile at high temperatures.

Wheel tracking test: For performing rut resistance test, the wheel tracking machine is used to simulate effect of traffic on asphalt concrete specimens. The asphalt roller compacter were used in this study according to British Standard (EN 12697-33), to prepare asphalt mixture slab of $(300 \times 400 \times 50 \mathrm{~mm})$. Different set of slab samples have been prepared with different mixture variables to perform wheel tracking test. The rutting resistance of (HMAC) is conducting in France using the specification EN 12697-22. For evaluating, the rut depth test, a stress of 80 Psi was applied to $(300, \mathrm{X} 200, \mathrm{X} 50 \mathrm{~mm}$ ) slab specimens subjected to a test temperature was $55^{\circ} \mathrm{C}$. Figure 11 and 12 showed that the rut depth was 16.15 and $2.55 \mathrm{~mm}$ for conventional and EME, respectively, for a specimens subjected to 80 Psi and a temperature of $55^{\circ} \mathrm{C}$ at base course but the rut depth was 15.1 and $2.43 \mathrm{~mm}$ for conventional and EME, respectively, for a specimens subjected to 80 Psi and a temperature of $55^{\circ} \mathrm{C}$ at binder course. These results indicates that using high modulus asphalt mixtures were significantly effective in reducing rut depth and increasing rutting resistance for a wide range and this attributed to high modules binder used in this mixture. Increase stress has effect negative on pavement structure and increase movement of pavement particle during service life and lead to large amount or rutting. It can be noticed from these (Fig. 8 and 9) that the maximum rut depth occurred with conventional mixture containing higher asphalt grade (40-50), higher temperature and higher stress applied. The asphalt binder (40-50) is softer than the asphalt binder (20-30), so that, using softer asphalt binder leads to higher amount of permanent deformation at the same test conditions.

Rutting depth percentage: Test results are plotted in Fig. 14 and 15, the rut depth percentage for HMAC is approximately 5.1 and $4.86 \%$ for base and binder course, respectively and lower than (AFNOR., 1999) that specified that rut depth percentage lower than $7.5 \%$. The results showed that high modulus asphalt concrete mixtures their improvement for resistance to permanent deformation higher than to conventional mixture.

Determination of binder richness modulus (K): Aggregate grading were separated on required and particular sives, surface area calculated and then determinatin richness modulus $(\mathrm{K})$. Richness modulus $(\mathrm{K})$ binder were calculated from the equation as in shown:

$$
\mathrm{K}=\frac{\mathrm{TL}}{\alpha_{*} \sqrt[5]{\Sigma}}
$$

According to French specification there are two types of (HMAC) for base course and binder course: for light traffic class 1 and for heavy traffic class 2 . Surface area value (where 10.147 and 10.2495 for base and binder course, respectively and calculated from Eq. 4. Density of aggregate correction coefficient value ( $\left.{ }_{(}\right)$where 1.011 for base and binder course and find by $(2.65 / \mathrm{Gse})$ and Gse equal to 2.62. Asphalt binder content value (TL) where 4.931 and 5.5 for base and binder course, respectively and calculated from the equation as showen Fig. 16. 
(a)

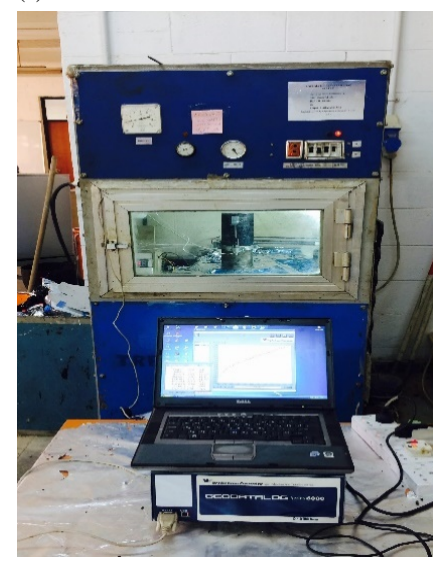

(b)

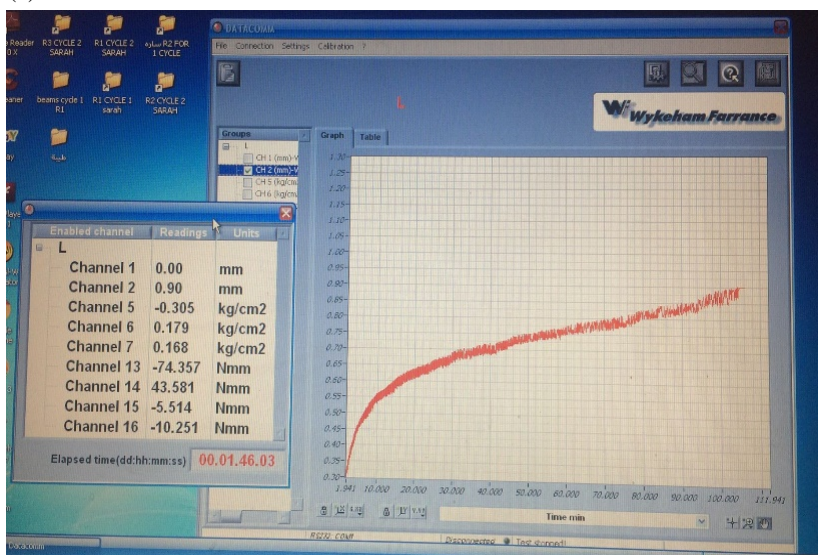

Fig. 10: a, b) Testing of specimen by Pneumatic Repeated Load System (PRLS)

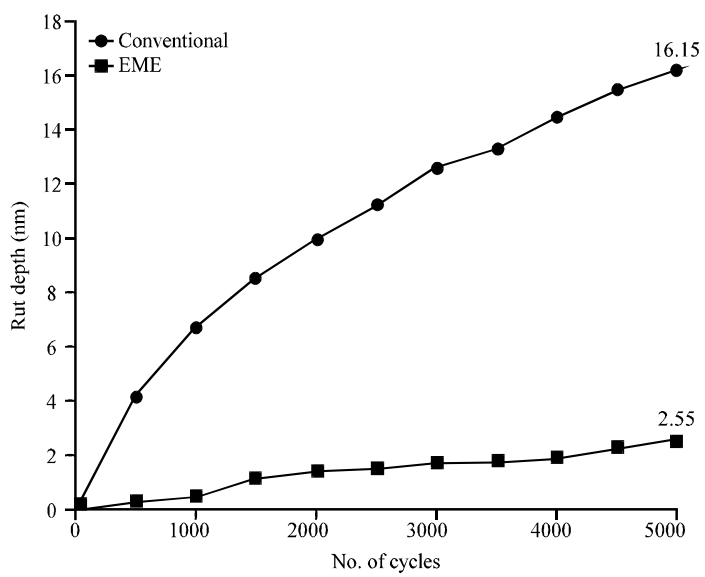

Fig. 11:Rut depth versus No. of load cycles at $55^{\circ} \mathrm{C}$ for base course

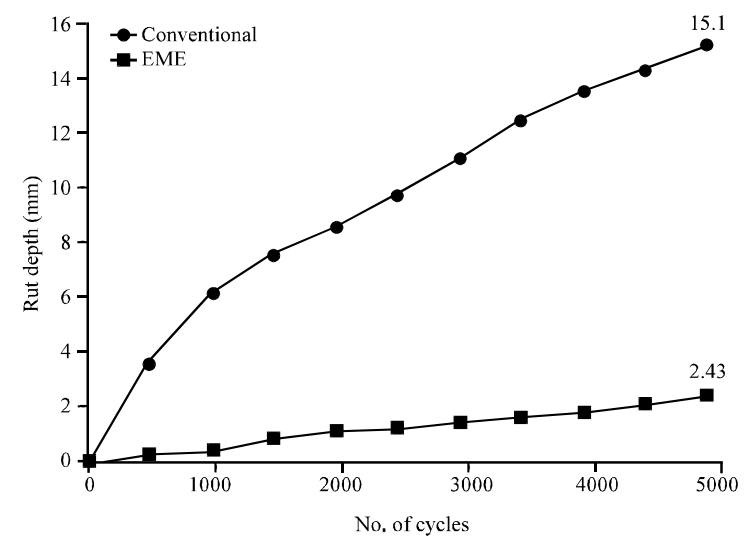

Fig. 12: Rut depth versus No. of load cycles at $55^{\circ} \mathrm{C}$ for binder course

$$
\mathrm{TL} \frac{100 * \mathrm{pb}}{100-\mathrm{pb}}
$$

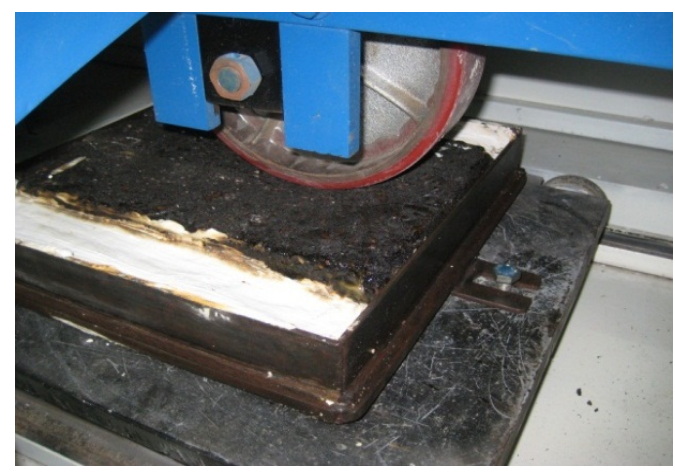

Fig. 13: Wheel tracking test

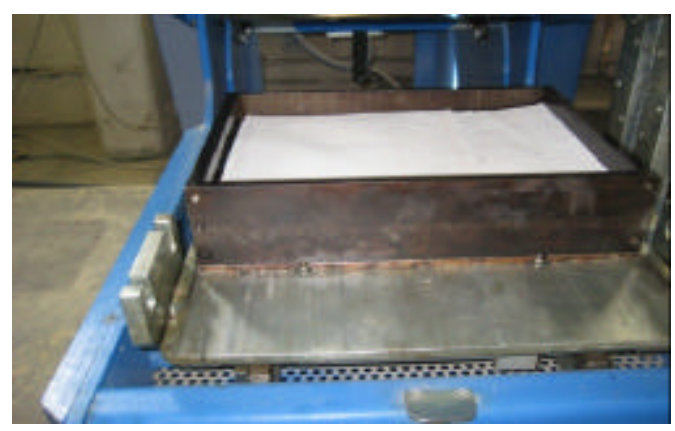

Fig. 14: Compaction of slab by roller compacter

Where:

$\mathrm{G}=$ Percent of Gradation larger than $6.3 \mathrm{~mm}$

$\mathrm{S}=$ Percent of gradation between 6.3 and $0.315 \mathrm{~mm}$

$\mathrm{s}=$ Percent of gradation between 0.315 and $0.08 \mathrm{~mm}$

$\mathrm{f}=$ Percent of gradation finer than $0.08 \mathrm{~mm}$

The value of $(\mathrm{K})$ obtained from the above equation was 3 and 3.4 for base and binder course, respectivly and 


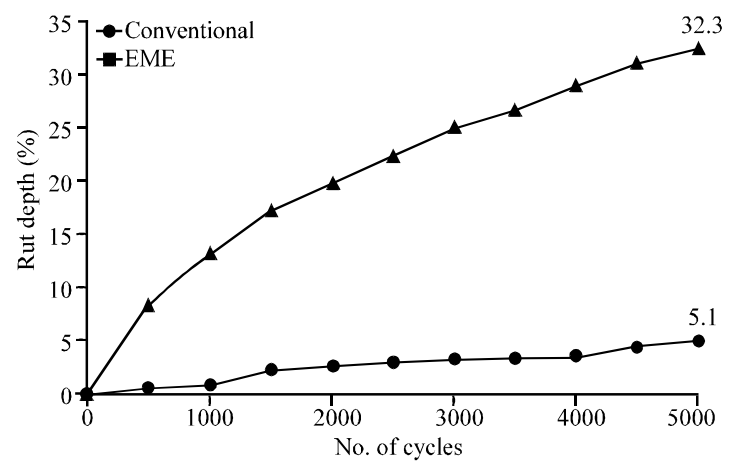

Fig. 15: Rut percentage for high modulus asphalt mixture compared to conventional mixture at $55^{\circ} \mathrm{C}$ for base course

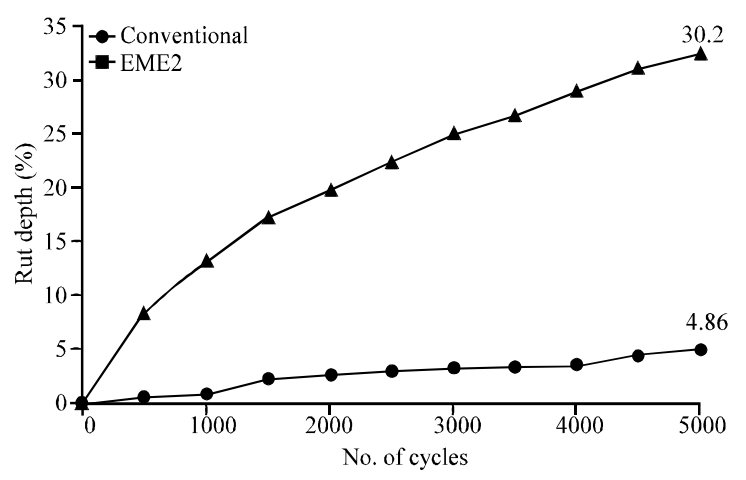

Fig. 16:Rut percentage for high modulus asphalt mixture compared to conventional mixture at $55^{\circ} \mathrm{C}$ for binder course

both value meet the criteria specified in (AFNOR., 1999) and as a result according to the value of $(\mathrm{K})$ the classification were (EME1) for base course and (EME2) for binder course.

\section{CONCLUSION}

Various test result were conducted to evaluate the use of high modulus asphalt concrete mixture in base and binder course. Laboratory program for different asphalt specimens including, resilient modulus and wheel tracking test. The obtained results from laboratory can be summarized as follow

Increasing temperatures from $\left(25-40^{\circ} \mathrm{C}\right)$, Resilient Modulus $\left(\mathrm{M}_{\mathrm{f}}\right.$ ) reduced by 65 and $20 \%$ for conventional and (EME) for base course while at the binder course the resilient modulus reduced by 59 and $16 \%$ for conventional and (EME), respectively.

Using (20-30) asphalt grade for EME mixes instead of (40-50) asphalt grade for conventional mixes for base and binder course at $55^{\circ} \mathrm{C}$ and 80 PSI for determination of permanent deformation causing an increasing in resistance of permanent deformation by 533 and $521 \%$ for base and binder course, respectively.

The rut depth percentage for the base course was 5.1 and $32.3 \%$ for EME and conventional, respectively while for the binder course were 4.86 and $30.2 \%$ for EME and conventional, respectively. Based on richness modulus $(\mathrm{K})$ in this study, the EME1 was achieved at base course while EME2 achieved at binder course. As the temperature and stress increased the permanent deformation resistance of conventional mixtures is reduced but still the (EME) has a higher resistance to deformation.

\section{ACKNOWLEDGEMENT}

Thanks are extended to the staff members of road materials laboratory at Civil Engineering Department/ University of Baghdad for the provision of work facilities throughout this study.

\section{REFERENCES}

AFNOR., 1999. [Hydrocarbon Envelopes-Layers: High Modulus Envelopes (EME)]. AFNOR French Standard, Paris, France, (In French).

Albayati, A.H., 2006. Permanent deformation prediction of asphalt concrete under repeated loading. Ph.D Thesis, University of Baghdad, Iraq.

Corte, J.F., 2001. Development and uses of hard-grade asphalt and of high-modulus asphalt mixes in France. Trans. Res. Circ., 503: 12-31.

Dias, M., L. Petho, E. Denneman and A. Beecroft, 2017. High Modulus High Fatigue Resistance Asphalt (EME2) Technology Transfer. Road Research Board Arrb Group Ltd., Australia, ISBN:9781925037937, Pages: 123.

Geng, H., C.S. Clopotel and H.U. Bahia, 2013. Effects of high modulus asphalt binders on performance of typical asphalt pavement structures. Constr. Build. Mater., 44: 207-213.

Huang, Y.H., 1993. Pavement Analysis and Design. Prentice Hall, River, New Jersey, USA., ISBN:9780136552758, Pages: 805.

Hunter, R.N., A. Self and J. Read, 2015. The Shell Bitumen Handbook. 6th Edn., ICE Publishing, UK, ISBN:9780727758378, Pages: 504.

Lee, H.J., J.H. Lee and H.M. Park, 2007. Performance evaluation of high modulus asphalt mixtures for long life asphalt pavements. Constr. Build. Mater., 21: 1079-1087. 
Moreno-Navarro, F., M. Sol-Sanchez, M.C. Rubio-Gamez and M. Segarra-Martuinez, 2014. The use of additives for the improvement of the mechanical behavior of high modulus asphalt mixes. Constr. Build. Mater., 70: $65-70$.

SCRB., 2003. General specification for roads and bridges: Section R/9 hot-mix asphalt concrete pavement. Ministry of Housing and Construction, State Corporation of Roads and Bridges, Republic of Iraq. http://procurement-notices.undp.org/view_file.cfm doc_id=99297

Sanders, P.J. and M.E. Nunn, 2005. The application of Enrobe a Module Eleve in flexible pavements. Master's Thesis, Transport Research Laboratory, Wokingham, UK.
Witczak, M.W., 2002. Simple Performance Test for Superpave Mix Design. SAGE Publications, New York, USA., ISBN:9780309067157, Pages: 105.

Wu, C., Y. Jia and Z. Feng, 2010. Performance evaluation pof polymer-modified asphalt binder in high-modulus.

Asphalt mixture. Proceedings of the 8th International Conference on Bearing Capacity of Roads, Railways and Airfields, May 1, 2010, CRC Press, CRC Press, Boca Raton, Florida, USA., ISBN: 9780203865286, pp: $1-7$.

Wu, C.Y., B. Jing and X.Y. Li, 2011. Performance Evaluation of High-Modulus Asphalt Mixture. In: Advanced Materials and Processes: ADME 2011, Guo, Z. (Ed.). Trans Tech Publications, Switzerland, ISBN:978-3-03785-214-9, pp: 2138-2141. 